\title{
Facebook ${ }^{\circledR}$ como Ferramenta Pedagógica em Saúde Coletiva: Integrando Formação Médica e Educação em Saúde
}

\author{
Facebook ${ }^{\circledR}$ as a Pedagogical Tool in Public \\ Health: Integrating Medical Training and \\ Health Education
}

Viviane Pereira Bernardes ${ }^{10}$ Lineker Fernandes Dias ${ }^{I \oplus}$ Monique Arantes Pereira ${ }^{\circledR}$ Maria Eduarda Fernandes ${ }^{1 \oplus}$ Gustavo Antonio Raimondi ${ }^{\text {Iอ }}$ Danilo Borges Paulino

PALAVRAS-CHAVE

- Educação em saúde.

- Educação médica.

- Rede social.

- Saúde pública.

- Medicina.
As mídias sociais conquistaram significativa importância na vida dos jovens contemporâneos, tanto no âmbito pessoal - para informação, divertimento - quanto no coletivo - para se projetarem como seres sociais e compartilharem informações com várias pessoas quase que instantaneamente. Diante disso, docentes da unidade curricular Saúde Coletiva III do curso de Medicina em uma universidade pública de Minas Gerais perceberam a influência do Facebook® na vida dos discentes e utilizaram-no para atingir objetivos de aprendizagem de conceitos e aplicações práticas de promoção em saúde e prevenção de agravos com a comunidade. A experiência foi conduzida durante dois semestres letivos consecutivos, por duas diferentes turmas do curso. Foi criada uma página do Facebook® com a finalidade de promover a saúde da população por meio de postagens criativas, críticas e acessíveis. Os acadêmicos tornaram-se protagonistas da atividade, uma vez que a escolha das temáticas, a busca ativa por fontes científicas de qualidade, a responsabilidade por cada postagem e o gerenciamento da página foram atribuídos a eles, sendo supervisionados pelos docentes. Obteve-se a interação com a comunidade para além da acadêmica, já que a página foi divulgada para atingir a população como um todo, contribuindo para a educação em saúde e consequentemente para a autonomia do cuidado pelos indivíduos. Dessa forma, as postagens dos discentes alcançaram muitos cidadãos, os quais, além de acessarem informações relevantes sobre saúde, podiam tirar dúvidas e fazer comentários sobre o tema. Portanto, a vivência permitiu o desenvolvimento de competências como Comunicação, Liderança, Atenção à Saúde e Administração e Gerenciamento, preconizadas nas Diretrizes Curriculares Nacionais. Entretanto, existem algumas limitações, como a necessidade de acesso à internet e a smartphones. À luz da vivência, pôde-se concluir que o uso de mídias sociais no curso de Medicina é uma forma efetiva de desenvolvimento de competências e de ampliação e consolidação do conhecimento, sendo os acadêmicos sujeitos fundamentais nesse processo, uma vez que a participação ativa deles é requisitada. Dessa forma, é proposta a replicação dessa experiência em outros ambientes de ensino-aprendizagem em Saúde, não somente pelo curso de Medicina, especialmente com utilização desse recurso pela Atenção Básica, favorecendo a formação de profissionais mais comprometidos com o cuidado integrado da população, em consonância com os princípios do Sistema Único de Saúde (SUS). 


\section{KEY-WORDS}

- Health Education.

- Education Medical.

- Social Networking.

- Public Health.

- Medicine.

\begin{abstract}
Social media has gained significant importance in the lives of contemporary youth, both personally for information, entertainment, and collectively - to project themselves as social beings and to share information with several people almost instantly. Thus, professors of Public Health curricular unit III, from the Medical School of a public university in Minas Gerais perceived the influence of Facebook ${ }^{\circledR}$ in the lives of students and used it to achieve concept learning objectives and practical applications of health promotion and prevention with the community. The experiment was conducted during two consecutive semesters, by two different classes of the course. A Facebook® page was created to promote the health of the population through creative, critical and accessible posts. The undergraduate students became the protagonists of the activity, since the choice of topics, the active search for highquality scientific sources, responsibility for each post and page management were attributed to them, while they were supervised by the professors. Interaction with the non-academic community was obtained, since the page was divulged to reach all the population, contributing to health education and consequent autonomy of care by the individuals. Thus, the students' posts reached many citizens, who, in addition to accessing relevant health information, could ask questions and make comments on the topic. Therefore, the experience allowed the development of skills such as Communication, Leadership, Health Care and Administration and Management, as recommended in the National Guideline for Undergraduate Medical Education. However, there are some limitations, such as the need to have access to the Internet and smartphones. Considering the experience, it was concluded that the use of social media in the medical course is an effective way of developing skills and expanding and consolidating knowledge, with the undergraduate students being central to this process, since their active participation is required. Thus, it is proposed to replicate this experience in other teachinglearning environments in Health, not only in Medical Schools, especially with the use of this resource by Primary Health Care, allowing the formation of professionals more committed to the integrated care of the population, in agreement with the principles of the Unified Health System (SUS).
\end{abstract}

Recebido: em 5/9/19

Aceito em: 16/9/19

\section{INTRODUÇÃO}

As Diretrizes Curriculares Nacionais (DCN) do curso de graduação em Medicina ${ }^{1}$ explicitam a necessidade de integrar ao ensino médico inovações que tornem o processo de aprendizagem mais dinâmico, com auxílio de metodologias com as quais o estudante exerça papel ativo na construção do conhecimento. Ademais, o documento aponta a relevância da incorporação de novas tecnologias de informação e comunicação que aprimorem a formação médica ${ }^{1}$.

Somam-se a esse contexto os avanços tecnológicos que possibilitaram maior acesso à internet e a proliferação de dispositivos pessoais, tais como smartphones e tablets, o que levou a transformações no ensino, na interação social e no compartilhamento de informações ${ }^{2}$. Assim, o uso da internet para acessar redes sociais tem atraído o interesse de educadores e de instituições no campo da educação médica ${ }^{3}$.

Nesse cenário em que as redes sociais podem ser utilizadas como aliadas no ensino médico, o Facebook ${ }^{\circledR}$ tem a sua participação na educação médica pesquisada em termos de profissionalismo médico e, em menor proporção, como ambiente de ensino e aprendizagem - em que se observa a formação de grupos para trocas de materiais e informações ${ }^{4}$.

O Facebook ${ }^{\circledR}$ difere de outras mídias sociais por oferecer uma variedade de ferramentas, reunindo diversas funcionalidades no mesmo local ${ }^{4}$. Ademais, os arquivos podem ser compartilhados em diversos formatos, tais como documentos, fotos e vídeos ${ }^{2}$. Aberto ao público desde 2006, é uma das redes sociais mais bem conhecidas no mundo atualmente ${ }^{5}$, sendo utilizada por $61 \%$ dos brasileiros em $2017^{6}$. É também a rede social com adeptos mais bem distribuídos entre as faixas etárias $^{7}$, ainda que no Brasil se verifique a maioria dos usuários entre 18 e 34 anos $^{8}$.

Entre os possíveis benefícios do uso do Facebook ${ }^{\circledR}$ na educação médica, destacam-se uma aprendizagem ativa por meio do engajamento do estudante, maiores oportunidades de feedback e desenvolvimento profissional ${ }^{9}$, a promoção da 
colaboração e da comunicação ${ }^{2}$, a facilitação de discussões sem restrições de tempo e espaço, e o uso disso para aperfeiçoamento do ensino-aprendizagem de profissionalismo e de princípios éticos na medicina ${ }^{10}$. Destaca-se que, em uma instituição pública brasileira, um estudo verificou que $99,7 \%$ dos discentes de Medicina usufruíam do Facebook® e 60,6\% o faziam diariamente para fins acadêmicos ${ }^{11}$. Em adição, $96 \%$ deles acreditam que o uso do Facebook ${ }^{\circledR}$ na graduação apresenta vantagens, entre as quais as mais destacadas foram facilidade, rapidez e compartilhamento de informações ${ }^{11}$.

Além disso, deve-se levar em consideração que a rápida difusão de informações promovida pelo Facebook ${ }^{\circledR}$ e a abrangência do seu alcance proporcionada pelo grande número de usuários o tornaram um instrumento valioso para a comunicação em saúde ${ }^{12}$ e, assim, para a promoção da saúde coletiva $^{13}$. Jha et al. ${ }^{5}$ afirmam que a enorme influência das redes sociais deve ser considerada como uma ferramenta poderosa de comunicação pelo sistema de saúde público, devendo ser adotada de maneira eficiente e oportuna. Campanhas de saúde veiculadas pelo Facebook $₫$ podem alcançar grande parte da população e permitem interações multidirecionais ${ }^{14}$. Além disso, Kite et al. ${ }^{13}$ indicam que novas informações sobre questões em saúde coletiva provocam alto nível de interesse e engajamento nas plataformas sociais.

Nessa esteira de discussão, vários trabalhos vêm explorando modos pelos quais o Facebook ${ }^{\circledR}$ vem integrando a promoção da saúde, entre os quais se observam o aconselhamento de métodos contraceptivos ${ }^{15}$, o uso consciente de antibióticos ${ }^{16}$ e campanhas para mudanças de comportamento, como a ingestão de álcool durante a gravidez ${ }^{17}$. No Brasil, essa rede também foi utilizada na educação em saúde sexual e reprodutiva pela Estratégia Saúde de Família a adolescentes ${ }^{18}$.

Assim, o papel que o Facebook $₫$ desempenha na promoção da saúde, possibilitada pela conexão com a comunidade, está em consonância com a potencialidade dele como recurso pedagógico para o ensino médico. A partir desse entendimento, foi proposto o desenvolvimento de atividades com a temática de Educação em Saúde utilizando essa rede social, com o propósito de promover a Educação em Saúde para além dos espaços habituais da consulta e do consultório médico. Destarte, o objetivo deste artigo é relatar a experiência - até então inédita na literatura - da utilização de uma página do Facebook® em um módulo de Educação em Saúde nas mídias de uma unidade curricular de Saúde Coletiva, no terceiro período do curso de Medicina de uma universidade federal brasileira.

\section{MÉTODO}

A atividade aqui relatada almejou promover e ampliar a formação em Educação em Saúde dos graduandos em Medicina e o diálogo com a comunidade por meio da utilização de uma mídia social. Inicialmente, os docentes apresentaram a proposta do uso de uma rede social pelos discentes, a qual deveria ser criada e gerenciada por estes ao longo do semestre letivo, com supervisão docente, tendo como finalidade o compartilhamento de informações para a Educação em Saúde. Essas informações deveriam ser atuais e de escolha dos discentes, que deveriam divulgá-las de forma bem embasada e atrativa para a comunidade em geral. A unidade do referido componente curricular em que se desenvolveu essa experiência foi denominada de "Educação em Saúde nas Mídias" e envolvia também uma aula realizada no aplicativo WhatsApp ${ }^{\circledR 19}$ e o desenvolvimento de uma Campanha de Educação em Saúde.

Motivados a estabelecer uma interação dialógica na construção de uma atividade que fizesse sentido para os discentes, os docentes não determinaram qual seria a rede social utilizada. Tanto a mídia quanto os respectivos critérios de condução e avaliação da atividade seriam estabelecidos coletiva e colaborativamente entre discentes e docentes, em um contrato pedagógico pactuado em sala de aula. A pontuação atribuída a essa atividade correspondia a $10 \%$ da nota total do semestre para o componente curricular.

Inicialmente, a turma, com 49 acadêmicos, foi dividida em nove equipes com cinco integrantes cada e uma equipe com quatro integrantes. Após a divisão, os discentes foram convidados a responder às seguintes perguntas que nortearam a condução da atividade durante o semestre:

- Qual rede social escolheremos como lócus da atividade?

- Qual será o papel/a responsabilidade da turma e de cada equipe com essa mídia social?

- Quais serão o caráter e o conteúdo das postagens?

- Qual será a periodicidade das postagens?

- Como serão feitas a busca e avaliação do material utilizado nas postagens?

- Que aspectos éticos, legais e acadêmicos deveremos levar em conta ao construirmos essa mídia social?

- Como dividir a responsabilidade dessa tarefa entre as equipes?

- Como acompanhar/avaliar o desenvolvimento ou não de cada postagem?

- Como convidaremos a comunidade e como incentivaremos a participação dela nesta atividade?

- Como realizaremos a comunicação com a comunidade por meio dessa rede social?

- Comogerenciar essa mídia social ao longo do semestre? 
- Como avaliar o trabalho realizado na rede social?

- Qual será o papel dos docentes nesta atividade?

- Como e quando fazer intervenções que potencializem o ensino-aprendizagem nesta atividade?

Assim, para desenvolver as competências do diálogo, do estabelecimento de consensos, da gestão de conflitos e do feedback, cada equipe de discentes teve até 30 minutos para discussão e estabelecimento das respostas para as perguntas colocadas. Em seguida, foi estabelecido um relator para apresentar as respostas de cada equipe, bem como as respectivas justificativas. Após a apresentação dos relatores, os demais integrantes de cada grupo poderiam complementar as falas apresentadas, conforme inscrição prévia para fala. Desse modo, os discentes construíram as argumentações com respeito entre eles para a condução da atividade durante o semestre.

Ao final, a turma estabeleceu um consenso e definiu todas as pactuações necessárias para o funcionamento da atividade ao longo do semestre letivo. Os estudantes optaram por criar uma página no Facebook ${ }^{\circledR}$. As justificativas apresentadas pelos discentes foram de que essa era uma rede social de uso comum a estudantes e demais pessoas da comunidade, bem como por ela apresentar a possibilidade de acesso a páginas públicas sem a necessidade de ter uma conta no aplicativo. Também foi estabelecido que, diante de qualquer necessidade de repactuação, todos esses aspectos poderiam ser revistos e adaptados conforme as necessidades de aprendizagem e funcionamento da atividade, inédita para o curso de Medicina em questão. Mantinha-se, assim, a construção dialógica da atividade ao longo de todo o processo.

Para a divulgação à comunidade, discentes e docentes convidaram todos os amigos que tinham nessa rede social para "curtirem" a página. Assim, eles seriam notificados sobre novas postagens e poderiam acompanhá-las na página pessoal. Todas as publicações deveriam ser compartilhadas e curtidas pelos discentes da turma, para alcançar mais usuários, conforme tinham pactuado no início da atividade por meio do contrato de convivência. Além disso, o interesse pela postagem poderia levar qualquer usuário a compartilhá-la. Os professores também divulgaram a página por e-mail a todos os contatos que tinham com professores da nossa e de outras universidades do país. No semestre seguinte, a nova turma optou por dar continuidade à página, ampliando o número de seguidores. Com 65 acadêmicos, formaram-se sete equipes com cinco integrantes cada e cinco equipes com seis integrantes.

Com relação às normas gerais para condução da atividade pedagógica ao longo do semestre e aos critérios de pontuação dela referidos na unidade curricular, as turmas que a vivenciaram pactuaram critérios avaliativos distintos, com algumas similaridades nos respectivos contratos pedagógicos, entre os quais, destacam-se: 1 . a periodicidade das postagens seria semanal; 2 . poderia ser postado um conteúdo referente a qualquer tema relacionado com saúde, com ênfase nas práticas de promoção, prevenção e educação em saúde ${ }^{1}$; 3 . todos os membros da equipe alcançariam a nota integral se, nessa atividade pedagógica, cumprissem tudo o que foi estabelecido no contrato pedagógico; 4 . cada equipe perderia meio ponto por dia de atraso após a data pactuada para a postagem; 5 . os membros de cada equipe ficariam responsáveis por interagir e estimular a interação com a sua respectiva publicação; 6. qualquer evento que não estivesse contemplado no contrato pedagógico seria debatido entre docentes e discentes para que, juntos, buscassem a melhor solução possível.

Na transição da atividade entre as turmas, houve mudanças na identificação da turma no nome da página e na repactuação da quantidade de grupos por postagens: no primeiro semestre, cada grupo ficou responsável por duas postagens, sendo uma delas compartilhada entre dois grupos. No semestre seguinte, cada grupo, separadamente, ficou responsável por apenas uma postagem durante todo o período. $\mathrm{O}$ intervalo entre cada nova publicação foi semanal em ambos, totalizando 15 e 12 postagens, no primeiro e no segundo semestres, respectivamente.

Este relato de experiência apresentará, em seus resultados e discussão, como ocorreu o desenvolvimento dessa atividade ao longo dos dois semestres letivos. Dessa forma, serão compartilhados os resultados positivos e os desafios não previstos e como lidou-se com eles. Além disso, será agregada discussão teórica pertinente às reflexões acerca da atividade aqui expressa, concluindo com as sugestões que essa experiência permite fazer para a reprodução e o aperfeiçoamento da experiência em outros contextos de ensino-aprendizagem.

Este relato de experiência foi construído pelos docentes idealizadores da experiência e discentes das turmas mencionadas. Ele se enquadra no item VIII do artigo $1^{\circ}$ da Resolução no 510, de 7 de abril de 2016, do Conselho Nacional de Saúde ${ }^{20}$, não necessitando de submissão ao Comitê de Ética em Pesquisa com Seres Humanos.

\section{RESULTADOS E DISCUSSÃO}

A página do Facebook ${ }^{\circledR}$ criada pela primeira turma de acadêmicos foi intitulada de "Saúde Coletiva", seguida pelo número da turma. O desafio era postar conteúdos semanais voltados para a temática de saúde, baseados em boas evidências científicas sobre o assunto e, ao mesmo tempo, em uma linguagem capaz de dialogar com diferentes públicos. Inicialmente cria- 
do para socialização, o Facebook ${ }^{\circledR}$ possui grande potencial educativo, já que permite a rápida difusão de conhecimento: quando o usuário gosta de uma determinada página do Facebook $\AA$, as postagens desta são expostas em sua página pessoal instantaneamente e, além disso, as postagens podem ser compartilhadas, alcançando um maior número de usuários ${ }^{21}$.

Dessa forma, foram utilizados vários recursos estéticos e visuais nas publicações feitas pelos discentes ao longo da experiência, como: vídeos, fotos, fluxogramas, entrevistas com profissionais, notícias, além de um texto sobre a temática, sempre informativo e objetivo. Isso está de acordo com a necessidade de ampliar o acesso a conteúdos científicos por meio das redes sociais ao fornecer mensagens concisas e informativas de qualidade com uma linguagem mais acessível e didática, de forma que não apenas seja alcançado o maior número de receptores, mas também que haja compreensão efetiva por parte deles ${ }^{22}$.

Os temas das postagens eram de livre escolha pelo grupo de discentes responsáveis por fazê-la, entretanto, a partir da observação dos problemas em saúde mais prevalentes na comunidade, houve uma priorização por esses temas, visto que tais problemáticas poderiam gerar maior visibilidade e impacto. Essa prática de promoção da saúde orientada por demanda social provavelmente ocorreu porque a atividade estava integrada a outras que estimulavam o diálogo e a assimilação de conceitos a respeito da Educação em Saúde na Atenção Primária, entendendo a relevância de uma educação problematizadora, em que a estratégia dialógica se torna fundamental ${ }^{23}$.

Nesse sentido, alguns temas abordados pela primeira turma envolvida na experiência foram: a terapia cognitiva baseada em mindfulness, o sedentarismo e a privação de sono, a promoção da saúde, síndrome de burnout, as estratégias para otimização do tempo, a autonomia e a saúde, o feedback como estratégia de solução de problemas, o estresse vivido por estudantes de medicina, a homofobia e o bullying, o Programa Saúde na Escola (PSE), a importância da empatia, a prevenção em saúde, a saúde e as mídias sociais.

Após definida a temática e elaborada a publicação na mídia social, os comentários dos seguidores da página acerca da postagem eram, também, subsequentemente respondidos pelos estudantes responsáveis pela publicação, que buscaram fazê-lo de forma clara, coesa e respeitosa. Visto isso, um aspecto de suma importância, disponibilizado em redes sociais como o Facebook®, é a possibilidade de atribuir uma espécie de feedback a uma publicação por meio das reações escolhidas pelos internautas de "curtir", "amar", "haha", "uau”, "triste", "grrr", quando, respectivamente, eles gostam, amam, divertem-se, surpreendem-se, entristecem-se ou se enraivecem com uma postagem. Essa ferramenta permitiu aos estudantes terem uma percepção de como suas postagens estavam sendo recebidas pela comunidade.

Com o feedback na educação médica, os estudantes constroem seu senso crítico e se tornam aptos a fazer uma autoavaliação. Portanto, as ferramentas da mídia social, ao estimularem a interação do aluno com seu conteúdo gerado, podem promover o aprendizado ativo por meio do engajamento em discussões e desenvolvimento da capacidade de dar e receber feedback ${ }^{9}$. O feedback das publicações, por meio das curtidas e dos comentários, serviu para o gerenciamento e a avaliação do progresso da página e da repercussão da rede social.

Já na primeira publicação, houve reações inesperadas com as quais a turma se deparou. A postagem que abordava o conceito de mindfulness foi questionada pela comunidade, em particular a acadêmica, por meio de comentário público, especialmente no que tange à qualidade das evidências científicas utilizadas para a construção da publicação e que subsidiavam tal prática. Esse foi o primeiro desafio enfrentado pela página, pois, devido à utilização do Facebook ${ }^{\circledR}$ como meio de comunicação, foi necessário aprender a lidar com a rápida popularização da indagação. Essa pode ser considerada genuína, uma vez que os conteúdos expostos em mídias sociais variam muito em qualidade, por isso os estudantes precisam ter habilidade em diferenciá-los em relação à sua qualidade para que haja efetividade no uso delas na educação ${ }^{2}$. Essa competência, que com frequência não é formalmente ensinada durante a graduação ${ }^{24}$, é imprescindível para que os futuros profissionais sejam capazes de adotar decisões de acordo com a melhor evidência científica, como preconizado pelas DCN ${ }^{1}$. Portanto, a experiência foi positiva para os estudantes, na medida em que suscitou a busca ativa por referências de qualidade para defesa dos resultados apresentados na postagem.

Além disso, o questionamento da comunidade gerou uma discussão na página, em que alguns estudantes da turma de graduandos envolvida na experiência fizeram uso de "memes", que são imagens ou vídeos humorísticos que se tornaram populares pela rápida propagação na internet, como forma de resposta aos questionamentos levantados pelo leitor. Essa mobilização em torno da postagem teve como consequências o aumento de curtidas da página e o maior engajamento dos discentes. Devido a esse conflito, na aula seguinte, foi aberto pelos docentes um espaço de escuta e de debate sobre essa situação de desentendimento para que fossem levantadas reflexões acerca desse episódio. Para isso, os estudantes foram convidados a refletir a partir da seguinte questão: "Se eu fosse o médico que cuida da pessoa que questionou o subsídio científico da postagem, de que forma eu responderia ao questionamento feito?". 
A partir dessas questões disparadoras, os discentes puderam trabalhar suas habilidades de comunicação e de resolução de conflitos, contidas nas diretrizes para a formação médica ${ }^{1}$. A abertura de espaços de discussão, de acordo com a Resolução nº 2.126/2015 do Conselho Federal de Medicina ${ }^{25}$, é necessária para a criação de um agir profissional com ética, competência e eficiência, pois favorece a capacidade de argumentação, de crítica construtiva e de reflexão acerca da educação médica em tempos de cultura digital, a fim de valorizar a solidariedade, o respeito mútuo e a convivência harmônica.

Ademais, os acadêmicos, como futuros médicos, puderam compreender que as opiniões, os comentários e a distribuição de conteúdo na internet sobre assuntos relacionados à saúde influenciam na percepção pública da profissão, podendo impactar a construção da relação médico-paciente ${ }^{26}$. Assim, ressalta-se a importância de os acadêmicos presenciarem oportunamente a experiência de educação em saúde por meio de mídias digitais, aprendendo a cautela, o planejamento, a responsabilidade e a ética de divulgar informações sobre saúde nas modernas redes sociais ${ }^{11}$.

Entre os pontos positivos alcançados com essa atividade, destaca-se a compreensão pelos discentes da necessidade de busca das melhores evidências científicas disponíveis para a confecção das publicações. Em adição, os discentes puderam compreender a repercussão da página junto à comunidade e, por conseguinte, a responsabilidade do conteúdo divulgado por meio dela. Portanto, durante esse momento de diálogo em sala de aula, construiu-se um maior sentimento de identificação e pertencimento em relação à página pela turma e foi pactuada a não utilização de "memes" para as respostas às indagações da comunidade, mas sim o uso do diálogo compreensivo e positivo.

No decorrer da execução da experiência, ainda com a primeira turma de estudantes, a publicação mais visualizada e que conquistou o maior número de "curtidas" abordou as consequências do sedentarismo e da privação de sono. Intitulada "Por que eu me esqueci de mim?", a postagem buscou promover o autocuidado, tendo por pilares, segundo a medicina baseada em evidências, a prática de exercícios físicos e a importância de uma boa noite de sono. O grupo de estudantes responsáveis pela postagem utilizou, em seu construto, estudos publicados em revistas de maiores fatores de impacto - o "fator de impacto", ao contabilizar as citações recebidas, torna-se uma ferramenta importante para avaliação de periódicos e consequentemente relevante para a busca de boas evidências -, como a Revista Brasileira de Epidemiologia, a Revista Brasileira de Medicina do Esporte, a Revista de Atenção à Saúde e a Neurobiologia.
Além disso, a referida publicação abordou a negligência de autocuidado dos estudantes universitários, ressaltando a importância de as universidades valorizarem e estimularem a prática de esportes e outros exercícios físicos entre discentes. Dessa forma, foi transcrita, na postagem, uma entrevista com um acadêmico, ex-presidente da Associação Atlética de Medicina, relatando os benefícios dos esportes individual e coletivo para a saúde e as relações sociais. Ademais, durante a criação do conteúdo dessa postagem, professores de outras unidades curriculares, uma educadora física, um cardiologista e um nutrólogo especialista em Medicina do Esporte foram contactados para entrevista em vídeo, com o propósito de promover uma integração entre as várias áreas do conhecimento para construção dos conteúdos publicados. Essa interdisciplinaridade é apontada como fundamental para a abordagem integral do processo saúde-doença ${ }^{27}$. A experiência, dessa forma, também foi enriquecedora, na medida em que ajudou a superar o modelo fragmentado das especialidades ao ocasionar uma ação conjunta que visa superar o modelo de educação tradicional $^{28}$.

Ainda sobre a publicação de maior repercussão, anexaram-se duas playlists - que são listas de reprodução de músicas pré-selecionadas em um aplicativo de música - de forma a permitir o seu compartilhamento entre todos aqueles leitores que buscassem músicas para ouvir durante a prática de exercícios, recomendação da própria postagem, ou, também, para relaxamento no momento do sono. Percebeu-se, por meio dos comentários, das curtidas e das reações à postagem, que a publicação atingiu vários segmentos sociais, com a interação da população e de estudantes de outras universidades no conteúdo divulgado.

Dando continuidade à experiência pedagógica, a segunda turma de graduandos publicou postagens referentes a temas como: o combate ao suicídio, a fibromialgia, o rastreamento do câncer de colo uterino, o movimento antivacina, os grupos operativos, a epidemia da dengue no Brasil, o rastreamento do câncer de próstata, a prevenção da prematuridade, o Dia Mundial do Acidente Vascular Cerebral (AVC), o Dia Nacional do Doador Voluntário de Sangue, a luta contra a Síndrome da Imunodeficiência Adquirida (Aids) e o transtorno de ansiedade.

Na segunda turma de graduandos, uma das postagens de maior repercussão abordou a campanha "Setembro Amarelo", que consiste em uma série de ações de vários segmentos da sociedade com o intuito de articular medidas para prevenção do suicídio no Brasil. O grupo de discentes responsáveis pela redação do conteúdo redigiu-o baseado em um artigo de revisão ${ }^{29}$, publicado na Revista Brasileira de Educação Médica, sobre 
esse tema entre médicos e estudantes de medicina, explicando à comunidade formas eficazes de buscar a redução de casos de suicídio, quais as principais causas e as taxas epidemiológicas desse agravo de saúde atualmente, com destaque para a alta incidência de suicídio entre os estudantes de medicina e médicos, quando comparados com outros grupos de estudantes e profissionais.

Ainda na mesma postagem, foi abordada a deficiência de estudos e de ações que buscam entender as causas e minimizar as consequências das doenças mentais na atualidade, considerando a hipótese de certa negligência dos cursos médicos em relação à saúde mental do estudante. Para tanto, utilizaram-se, nessa parte do conteúdo, imagens explicativas, assim como campanhas motivacionais para completar a publicação. Na página, promoveu-se também uma campanha sobre a doação de sangue que foi muito compartilhada entre os seguidores, o que aumentou bastante o alcance da mensagem entre os usuários do Facebook®. A utilização dessa plataforma social como aliada para a divulgação de campanhas pela Saúde Pública já é reconhecida ${ }^{13,14,16}$ e deve ser incentivada na formação em saúde.

A segunda postagem mais "curtida" e compartilhada dessa turma abordou a fibromialgia, tema em destaque devido ao impedimento de uma celebridade internacional de se apresentar à época em um show no Brasil. Buscava-se compartilhar maior conhecimento a respeito dessa enfermidade, por meio de respostas objetivas às perguntas: "o que é?”, "o que causa?", "como é o tratamento?", "como prevenir?"; deixando o link da fonte utilizada disponível para consulta - um artigo da Revista Brasileira de Reumatologia ${ }^{30}$. Esse exercício, pelos discentes de Medicina, de compartilhar informações de saúde com a comunidade de forma interativa, desde a graduação, pode colaborar com a formação de profissionais mais comprometidos com a educação em saúde. Inseridos em uma realidade virtual, em que no Facebook $₫$ há discussões sobre determinadas condições de saúde por meio de suas páginas, das quais $32,2 \%$ apresentam conteúdos comerciais, enquanto $20 \%$ se destinam à propagação de conteúdos científicos ${ }^{31}$, é sugerido que os médicos sejam incumbidos de disponibilizar em redes sociais informações de saúde confiáveis ${ }^{32}$.

Outra publicação abordou o movimento antivacina, para problematizar com os internautas essa temática. Particularmente sobre temas que estimulam muitas discussões na saúde, como a vacinação, o Facebook® demonstra ser uma plataforma que facilita debates ${ }^{33}$ e pode contribuir para estratégias de vacinação ${ }^{34}$. Por isso, foi constatado que, apesar de menos curtidas, a postagem gerou maior interação com a comunidade, por meio de comentários que questionavam a segurança das vacinas, problematizando as reações adversas delas e os componentes biológicos que possuem.

As afirmações e indagações feitas pela comunidade demonstram o quanto esse assunto necessita ser debatido com profissionais de saúde, principalmente quando se considera que a facilitação ao acesso às informações nem sempre está aliada ao compromisso com a veracidade contida nelas. Essa preocupação é corroborada pela literatura, em que já se demonstrou que a distribuição de informações falsas veiculadas nas mídias sociais podem ter impactos na saúde da população, uma vez que $46,6 \%$ dos usuários da saúde admitiram iniciar medicações sem consultar um médico após visualização de propagandas em redes sociais e $42,2 \%$ interromperam um tratamento após ler textos nessas plataformas ${ }^{32}$.

Também se ressalta, nessa experiência, que um recurso bastante utilizado pelos discentes, nas postagens, foi a associação de textos com pequenos vídeos, um dos quais chegou a ser visualizado mais de 400 vezes. Nesse vídeo, uma docente da própria universidade, pediatra neonatologista, foi consultada pelos graduandos para uma gravação acerca do Novembro Roxo, campanha de prevenção da prematuridade pouco conhecida pela comunidade até então. Esse alcance consideravelmente maior de usuários, quando comparado a outras postagens, está de acordo com pesquisa recente feita na América Latina em que foi constatado o dobro de compartilhamentos e de visualizações no Facebook ${ }^{\circledR}$ de postagens que continham vídeos $^{35}$. Com isso, conclui-se que tendências para a diferente elaboração das postagens podem ser estudadas para favorecer a difusão de saberes em saúde.

Destaca-se também que a oferta de comunicação científica de forma lúdica e com textos concisos e bastante informativos é uma necessidade atual em que o ritmo cotidiano das pessoas é acelerado, e o tempo, escasso ${ }^{22}$. Nesse contexto, a utilização do Facebook ${ }^{\circledR}$ por médicos como aliado encontra-se muito distante da sua potencialidade ${ }^{22}$. Visto isso, a prática pelos discentes de sintetizar informações científicas obtidas em artigos e associar com recursos midiáticos permite o desenvolvimento de competências que os prepara para a prática da Educação em Saúde em meio às novas tecnologias.

A utilização excessiva das redes sociais, entretanto, cria limitações no uso do Facebook ${ }^{\circledR}$ como ferramenta, uma vez que há níveis variados de participação dos estudantes e mais tempo despendido na página social ${ }^{9}$, com risco de promover comportamento vicioso, possíveis efeitos colaterais, como dor de cabeça e distúrbios do sono ${ }^{5}$, além de problemas de privacidade e profissionalismo ${ }^{2}$. Porém, segundo Curran et al. ${ }^{2}$, um modo efetivo de adoção e uso de tecnologia como modo de educação formal seria a separação do uso profissional e 
pessoal da ferramenta, como desenvolvido em nossa atividade. Ademais, nessa experiência, o engajamento de todos os estudantes foi requisitado de forma equilibrada e pactuada, na medida em que houve divisão prévia de atribuições entre todos, além de claros critérios avaliativos.

Assim, os acadêmicos se tornaram protagonistas da atividade ao pensarem, refletirem, elaborarem e compartilharem assuntos de interesse em saúde no Facebook ${ }^{\circledR}$, de forma a valorizar o ensino-aprendizagem que se estabelece na relação docente-discente ${ }^{36}$, o que contribui para a incorporação e o aprofundamento de conhecimentos ${ }^{37}$. Os docentes, em seu papel de supervisionar o andamento da atividade, cumpriram o papel de facilitadores do conhecimento proposto pelo modelo radical de educação em saúde ${ }^{38,39}$. Além de acompanharem todas as atividades, os docentes foram acionados em momentos em que os estudantes se encontravam inseguros para proceder diante de dilemas éticos, gestão de conflitos e quando necessitavam de apoio e de fontes seguras de informação.

Faz-se necessário indicar possíveis limitações da experiência, como a necessidade de internet, assim como de dispositivos eletrônicos como notebooks ou smartphones. A falta de acesso ao Facebook® poderia ser superada com a utilização de cópia das postagens impressas ou projetadas, por exemplo, em rodas de conversa com a comunidade. Dessa forma, a página produz conteúdo que pode ser obtido por uma única pessoa que tenha acesso a essa rede social e multiplicado a diversas outras que não o possuem.

Outras experiências de educação utilizando o Facebook® constataram a participação variável dos graduandos ${ }^{40}$. No entanto, essa experiência minimizou possíveis diferenças de engajamento ao distribuir homogeneamente e de forma dialógica as tarefas para cada participante, com o estabelecimento prévio de um contrato pedagógico de mútuo acordo entre discentes e docentes, o que favoreceu o respeito e o sentimento de responsabilidade entre os envolvidos. Essa experiência, juntamente com a aula realizada no aplicativo WhatsApp ${ }^{\circledR}{ }^{19}$, foi apresentada, em 2018, no I Congresso da Associação Brasileira de Pesquisa em Prevenção e Promoção da Saúde (Brapep), com o tema "Desafios da pesquisa em prevenção e promoção da saúde em contextos de iniquidades sociais". Por conta desse trabalho, os autores foram contemplados com o título de Menção Honrosa.

\section{CONSIDERAÇÕES FINAIS}

Demonstra-se uma forma de utilização de uma plataforma social, o Facebook ${ }^{\circledR}$, em que se complementam a Educação Médica e a Educação em Saúde. Entre os benefícios constatados nessa experiência com a utilização do Facebook® como recurso pedagógico, destacam-se: engajamento dos discentes com participação ativa no processo de aprendizagem, maiores oportunidades de feedback, comunicação entre os pares e a comunidade, prática dos princípios de ética e profissionalismo no contexto da globalização, e exercício da medicina baseada em evidências por meio da procura ativa de referências de qualidade para elaboração das postagens.

Identificou-se ainda que a atividade realizada na unidade curricular Saúde Coletiva III proporcionou a interação com docentes de outros componentes curriculares durante a elaboração de postagens. Destarte, a Educação em Saúde por meio dessa mídia social poderia ser reproduzida em outras unidades curriculares do curso, transformando o conhecimento científico aprendido no ambiente acadêmico em conteúdo com linguagem acessível e de interesse da comunidade, o que também ajudaria na consolidação de conceitos.

Com essa experiência, busca-se também estimular a ampliação para outros locais de aprendizagem em saúde e a utilização dos recursos propostos pela Atenção Primária em Saúde, com incentivo à participação dos acadêmicos, os quais, como futuros profissionais médicos, formar-se-ão mais comprometidos com as reais necessidades populacionais, favorecendo a promoção da saúde e prevenção de agravos. Assim, propõe-se a criação de páginas do Facebook ${ }^{\circledR}, \operatorname{com}$ auxílio de estudantes não somente de Medicina, mas em conjunto com outros cursos da área de saúde, como ferramenta útil para a Educação em Saúde, a fim de promover a interdisciplinaridade e o trabalho em equipe entre as diversas profissões que constroem o cuidado integral em saúde.

\section{AGRADECIMENTOS}

Agradecemos à Universidade Federal de Uberlândia (UFU) pelo reconhecimento deste projeto, juntamente com a aula desenvolvida no aplicativo WhatsApp $\AA$, com conquista da Menção Honrosa no Prêmio Inovação UFU 4.0 em outubro de 2019. Agradecemos a todas as pessoas e setores de nossa instituição que tornaram essas atividades possíveis. Agradecemos ao Programa FAIMER® Brasil o apoio e a formação compartilhados para que essa e outras experiências de aprimoramento da Educação Médica em nossa instituição fosse possível. Agradecemos à Faculdade de Medicina, ao Departamento de Saúde Coletiva e ao curso de Medicina da instituição que nos apoiaram na participação no Programa FAIMER® Brasil e na concretização deste projeto. Agradecemos aos discentes das turmas do curso de Medicina da Universidade Federal de Uberlândia, que participaram de forma ativa na execução desta proposta. Agradecemos aos acadêmicos Alexandre Cesar Alves de Castro, Nathaniel Lucas Soares Lima, Pedro 
Henrique Cerqueira, Raíssa Fragoso e Rebeca Raissa Bezerra de Oliveira, com os quais a escrita deste relato foi idealizada e recebeu o título de Menção Honrosa no I Congresso da Associação Brasileira de Pesquisa em Prevenção e Promoção da Saúde (Brapep), em Brasília, no ano de 2018. Agradecemos às acadêmicas Bruna Carolina de Oliveira e Marcela Araújo de Oliveira Santana, monitoras do Módulo Saúde Coletiva III durante o ano de execução desse projeto, pelo apoio e auxílio na condução desse.

\section{REFERÊNCIAS}

1. Brasil. Ministério da Educação. Conselho Nacional de Educação. Câmara de Educação Superior. Resolução CNE/ CES n 3, de 20 de junho de 2014. Institui Diretrizes Curriculares Nacionais do Curso de Graduação em Medicina e dá outras providências. Diário Oficial da União. Brasília, 20 jun. 2014, seção 1, p. 8-11.

2. Curran V, Matthews L, Fleet L, Simmons K, Gustafson DL, Wetsch L. A review of digital, social, and mobile technologies in health professional education. J Contin Educ Health Prof. 2017;37(3):195-206.

3. Hendrix D, Chiarella D, Hasman L, Murphy S, Zafron ML. Use of Facebook in academic health sciences libraries. J Med Libr Assoc. 2009; 97:44-47.

4. Pander T, Severin P, Dimitriadis K, Fischer MR. The use of social media in medical education: a literature review. GMS Z Med Ausbild. 2014;31(3):1-19.

5. Jha A, Lin L, Savoia E. The use of social media by State Health Departments in the US: analyzing health communication through Facebook. J Community Health. 2015; 41(1):174-179.

6. Statista Research Department. User penetration rate of Facebook in Brazil in 2017 and 2018. Statista. 2018. Disponível em: https:/ / www.statista.com/statistics/782571/facebook-penetration-rate-brazil/. Acesso em: 15 mai. 2019.

7. UKOM. Facebook Snapchat: Age Profiles. 2019. Disponível em: https://ukom.uk.net/insights/36-facebook-snapchat-age-profiles.php. Acesso em: 15 mai. 2019.

8. Statista Research Department. Distribution of Facebook users in Brazil as of January 2018, by age group and gender. 2018. Disponível em: https://www.statista.com/ statistics/198923/age-distribution-of-users-facebook-brazil/. Acesso em: 15mai. 2019.

9. Cheston CC, Flickinger TE, Chisolm MS. Social media use in medical education. Acad Med. 2013;88(6):893-901.

10. Ho A, Hee N, Teo R. Facilitating co-learning of medical ethical issues using Facebook. Med Educ. 2018;52(5):560561.
11. Purim K, Tizzot A. Protagonismo dos Estudantes de Medicina no Uso do Facebook na Graduação. Rev Bras Educ Med. 2019;43(1):187-196.

12. Masic I, Sivic S, Toromanovic S, Borojevic T, Pandza H. Social networks in improvement of health care. Mater Socio Medica. 2012;24(1):48-53.

13. Kite J, Foley BC, Grunseit AC, Freeman B. Please like me: Facebook and public health communication. PLoS One. 2016;11(9):1-16.

14. Platt T, Platt J, Thiel DB, Kardia SLR. Facebook advertising across an engagement spectrum: a case example for public health communication. JMIR Public Heal Surveill. 2016;2(1):1-12.

15. Kofinas JD, Varrey A, Sapra KJ, Kanj RV, Chervenak FA, Asfaw T. Adjunctive social media for more effective contraceptive counseling. Obstet Gynecol. 2014;123(4):763770.

16. Zowawi HM, Abedalthagafi M, Mar FA, Almalki T, Kutbi $\mathrm{AH}$, Harris-Brown T, et al. The potential role of social media platforms in community awareness of antibiotic use in the gulf cooperation council states: luxury or necessity? J Med Internet Res. 2015;17(10):1-12.

17. Parackal M, Parackal S, Eusebius S, Mather D. The use of Facebook advertising for communicating public health messages: a Campaign Against Drinking During Pregnancy in New Zealand. JMIR Public Heal Surveill. 2017;3(3):1-9.

18. Aragão JMN, Gubert FA, Torres RAM, da Silva ASR, Vieira NFC. O uso do Facebook na aprendizagem em saúde: percepções de adolescentes escolares. Rev Bras Enferm. 2018; 71(2):286-292.

19. Paulino DB, Martins CCA, Raimondi GA, Hattori WT. WhatsApp ${ }^{\circledR}$ como recurso para a educação em saúde: contextualizando teoria e prática em um novo cenário de ensino-aprendizagem. Rev Bras Educ Med. 2018;42(1):171-180.

20. Conselho Nacional de Saúde. Brasil. Resolução n 510, de 7 de abril de 2016. Diário Oficial da União, 7 abr. 2016, seção 1, p. 44-6.

21. Lugo-Fagundo C, Johnson MB, Thomas RB, Johnson PT, Fishman EK. New frontiers in education: Facebook as a vehicle for medical information delivery. J Am Coll Radiol. 2016; 13(3):316-319.

22. Ashammakhi N. Dissemination of information: from the stone age to the social media of Facebook. J Craniofac Surg. 2017;28(7):1645-1646.

23. Reis TC, Fernanda M, Figueiredo S, Paulo L, Rodrigo J, Karenina $\mathrm{A}$, et al. Educação em saúde: aspectos históricos no Brasil. J Heal Sci Inst. 2013;31(2):219-223. 
24. Scott KR, Hsu CH, Johnson NJ, Mamtani M, Conlon LW, Deroos FJ. Integration of social media in emergency medicine residency curriculum. Ann Emerg Med. 2014;64(4):396404.

25. Conselho Federal de Medicina. Resolução CFM $n^{\circ}$ 2.173/2017. Diário Oficial da União, 15 dez. 2017, seção 1, p. 50 .

26. Simpkin AL, Walesby KE. Training tomorrow's doctors. Futur Hosp J. 2017; 4(1):56-60.

27. Garcia MAA, Pinto ATBCS, Odoni APC, Machado LI, Linek MDS, Costa NA. A interdisciplinaridade necessária à educação médica. Rev Bras Educ Med. 2007;31(2):147-155.

28. Machado MMBC, Batista SHSS. Interdisciplinaridade na Construção dos Conteúdos Curriculares do Curso Médico. Rev Bras Educ Med. 2012;36(4):456-462.

29. Della Santa N, Cantilino A. Suicídio entre Médicos e Estudantes de Medicina: Revisão de Literatura. Rev Bras Educ Med. 2016; 40(4):772-780.

30. Provenza J, Pollak D, Martinez J, Paiva E, Helfenstein M, Heymann R, et al. Fibromialgia. Rev Bras Reumatol. 2004; 44(6):443-449.

31. Hale TM, Pathipati AS, Zan S, Jethwani K. Representation of health conditions on Facebook: content analysis and evaluation of user engagement. J Med Internet Res. 2014;16(8):1-16.

32. Iftikhar R, Abaalkhail B. Health-seeking influence reflected by online health-related messages received on social media: cross-sectional survey. J Med Internet Res. 2017;19(11):1-12.

33. Orr D, Baram-Tsabari A, Landsman K. Social media as a platform for health-related public debates and discussions: the Polio vaccine on Facebook. Isr J Health Policy Res. 2016; 5(1):1-11.

34. La Torre G, Miccoli S, Ricciardi W. The Italian alliance for vaccination strategies: Facebook as a learning tool for preventive medicine and public health. Hum Vaccin Immunother. 2014; 10(10):2910-2914.

35. Carvalho P. O conteúdo de vídeo em mídias sociais cresce $67 \%$ na América Latina. Comscore. 2017. Disponível em: https://www.comscore.com/Insights/Press-Releases / 2017 /3 / O-conteudo-de-video-em-midias-sociais-cresce-67-na-America-Latina. Acesso em: 15 mai. 2019.
36. Freire P. Pedagogia da autonomia: saberes necessários à prática docente. 56. ed. Rio de Janeiro, São Paulo: Paz e Terra; 2018.

37. Quintanilha LF. Inovação pedagógica universitária mediada pelo Facebook e YouTube: uma experiência de ensino-aprendizagem direcionado à geração-Z. Educ em Rev. 2017;65:249-263.

38. Souza AC de, Colomé ICS, Costa LED, Oliveira DLLC de. A educação em saúde com grupos na comunidade: uma estratégia facilitadora da promoção da saúde. Rev Gaúcha Enferm. 2005;26(2):147-153.

39. Mitre SM, Siqueira-Batista R, Ezequiel MA. Metodologias ativas de ensino-aprendizagem na formação profissional em saúde: debates atuais. Ciênc. Saúde Col. 2008;12:21332144.

40. Gray K, Annabell L, Kennedy G. Medical students' use of Facebook to support learning: insights from four case studies. Med Teach. 2010;32:971-976.

\section{CONTRIBUIÇÃO DOS AUTORES}

Danilo Borges Paulino e Gustavo Antonio Raimondi foram os responsáveis pela idealização e confecção do projeto que originou este relato de experiência, participando ativamente das demais etapas de elaboração deste texto. Todos os demais autores participaram da execução do projeto e da redação e revisão do manuscrito.

\section{CONFLITO DE INTERESSES}

Os autores declaram não haver conflitos de interesses neste estudo.

\section{ENDEREÇO PARA CORRESPONDÊNCIA}

Danilo Borges Paulino. Universidade Federal de Uberlândia, Faculdade de Medicina, Departamento de Saúde Coletiva, Avenida Pará 1720, Campus Umuarama, Bloco 2U, Sala 8, Umuarama, 38405-320, Uberlândia, Minas Gerais, Brasil. dbpaulino@ufu.br 